\title{
Experimental characterization and modelling of polyethylene terephthalate preform for injection stretch blow moulding
}

\author{
Battini $\mathrm{D}^{1 *}$, Avanzini $\mathrm{A}^{1}$, Antonini $\mathrm{M}^{2}$, Fausti $\mathrm{D}^{2}$, Mor $\mathrm{M}^{2}$, Vertuan $\mathrm{A}^{2}$, Chiesa $\mathrm{F}^{3}$, Grazioli $\mathrm{M}^{3}$, Donzella $\mathrm{G}^{1}$ \\ ${ }^{1}$ University of Brescia, Department of Mechanical and Industrial Engineering, via Branze, 38 - 25123 Brescia (BS) - Italy \\ 2 Polibrixia srl, via Branze, 45 - 25123 Brescia (BS) - Italy \\ ${ }^{3}$ SMILAB srl, via Vittorio Veneto, 4 - 24016 San Pellegrino Terme (BG) - Italy \\ *Corresponding author: e-mail: davide.battini@unibs.it, ph: +39030 3715807
}

\begin{abstract}
Polyethylene terephthalate (PET) is a widely used polymer in the production of bottles by injection stretch blow moulding (ISBM). In this work, we present a characterization method to identify material properties directly from a preform, considering temperature and stress-relaxation effects related to its viscoelastic response. A customized oven and gripping system were designed to perform uniaxial tests in a proper temperature range on tubular specimens obtained from preforms. A visco-hyperelastic model is then proposed: a Marlow-type strain energy function coupled with a Prony series and William-LandelFerry equation to include time and temperature dependency. Finally, a case study of ISBM process is implemented in a finite element code considering this constitutive model. Strain maps and predicted thickness of the bottle wall were evaluated as process quality indicators. Simulation results showed good agreement with measurements on the real processed bottle, confirming the usefulness of the approach for product or process parameters optimization.
\end{abstract}

\section{KEYWORDS}

Polyethylene terephthalate, PET, bottle, injection stretch blow moulding, ISBM, preform, finite element, FEM, experimental characterization

\section{INTRODUCTION}

Nowadays, polymeric drink containers are widespread and polyethylene terephthalate (more commonly known as PET) is widely used for their production, due to its characteristics of lightweight, transparency and high impact strength. The production of water bottles and soft drinks containers is usually a twostage process (see Fig.1). At first, the so-called preforms are prepared through an injection moulding operation and then stored. When required, the preform is reheated to be processed, for the most common case, with an injection stretch-blow moulding (ISBM), which transforms the preform in the final shape of the container. Some manufacturers are also offering machines that can produce the container directly from the PET resin by carrying out both the stages sequentially inside a single machine. Even if the process is well consolidated at the industrial level, guaranteeing and maintaining product quality is not easy since even small changes of the process parameters can affect its efficiency and outcome. The correct process set-up often remains a mixture of operator experience and trial and error approaches. The development of predictive tools would help improving the robustness of the process and help facilitating 
innovations in terms of product design (i.e. light weighting for emission reduction) by reducing the expensive and time-consuming experimental campaigns. In the past years, this motivated several works concerning methods to set up reliable ISBM models to investigate the role of plunger movement, gas pressures or other process parameters on the resulting wall thickness of bottles.

Proposed approaches for ISBM modelling are quite varied, ranging from the use of advanced fluid dynamics software for thermal finite element volumic calculation (Gupta et al., 2013) to the so-called "constrained natural elements method" (Cosson et al., 2008), but most of the research groups based their simulations on the Finite Element (FE) method. Quite obviously, constitutive modelling of PET mechanical response represents a key point for accurate predictions on the final wall thickness and evaluations on the influence of process parameters. PET mechanical behaviour has been extensively studied in the past, and it has been shown to be dependent on time, thermal and strain histories (as for many polymers (Avanzini and Gallina, 2011)). Furthermore, for the large deformation regime, its mechanical response is highly non-linear, exhibiting strain softening at first and then strain hardening due to a microstructural evolution. Reproducing such complex mechanical behaviour in the context of ISBM simulations remains a critical issue. In fact, many types of constitutive laws were proposed to account for strain rate sensitivity, viscous response and temperature effects and each law has associated benefits and drawbacks. As an example, PET has been considered as viscoelastic (when modelling flow during moulding with an updated-Lagrangian finite element method) (Schmidt et al., 1996), visco-plastic (Chung, 1989) or non-Newtonian creeping material (Wang et al., 2000). Due to the large deformation expected during the process, hyperelastic constitutive models based on the definition of a strain energy function represent another possible approach for the description of PET. Many hyperelastic models are already implemented in commercial software, making it easier to represent complex phenomena such as softening and hardening, but they usually not include any time or temperature dependency.

For this reason, in the context of ISBM modelling, standard hyperelastic formulations must be modified, as done for example in (Pham et al., 2004) in which a visco-hyperelastic model was used to describe the stretching behaviour of the polymer. Since these models are essentially empirical and phenomenological, it may be challenging to design proper experiments to generate the data required for material parameters fitting at representative ISBM strain rates and temperatures. A possible alternative is to use physicallybased models, as those originated from molecular network theory. In particular, Buckley's model, a physically based glass-rubber constitutive model originally developed by Buckley and Jones (Buckley, 1995) and augmented by (Adams et al., 2000), has been applied to PET to represent the mechanical behaviour near the glass transition temperature. According to this model, it is assumed that PET stores energy by two mechanisms: perturbation of interatomic potentials and perturbation of configuration entropy. This model has been implemented in simulations with direct pressure input or constant mass flow air in order to simulate ISBM to compare volume-time curves and the evolution of preform shape (Tan et al., 2008). More recently, Buckley's model has been used in (Zimmer and Stommel, 2013) to examine bottle wall thickness, material distribution, temperature, and strain and stress fields during the process. Since this model is based on a physical description of the material, it is capable to encompass the full range of behaviours exhibited by PET during industrial drawing processes. On the other hand, the determination of its parameters can be very challenging and requires complex chemical tests. In addition, its mathematical formulation is harder to implement in a finite element simulation.

Buckley's model has also been modified and extended more with a Lagrangian logarithmic strain space formulation in (Raza et al., 2019) by Raza et al.. Recently, in (Luo et al., 2016) Luo et al. even discussed that PET can show anisotropic visco-hyperelastic properties during the ISBM process.

Some researchers also pointed out that modifications occurring to microstructure during the PET blow stretching for the different phases of ISBM are likely to control the process in terms of end-use properties of the final part (Yan et al., 2017). These phenomena are not yet completely understood but lead toward the development of a new class of constitutive model as discussed in (Billon et al., 2014; Cosson et al., 
2012).

Independently of the theoretical background, every constitutive model requires proper experimental testing to identify all the material parameters. While testing PET specimens under uniaxial load is the most common option, biaxial tests are often recommended as they should allow (under the assumption of isotropic behaviour) a complete characterization of the material in a stress condition close to the one experienced during the ISBM process (Awaja and Pavel, 2005; Fu and Ogden, 2001; Holzapfel, 2000; Luo et al., 2013; Menary et al., 2012). Unfortunately, appropriate biaxial devices for this application are not readily available, especially if we consider the high strain rate and high temperature range at which the tests should be carried out.

A further critical aspect is that virgin material is usually tested, due to the ease of creating suitable samples for tensile or biaxial testing. However, preforms undergoing the ISBM process could be significantly different from virgin PET since preforms experience thermo-mechanical processes that heavily modify their shape and properties. For this reason, investigating the uniaxial response of the material on a "preformed" specimen would help characterizing the material in an as-representative-aspossible state.

In this study, an original experimental procedure for ISBM material characterization is thus presented: a standard servo-hydraulic test machine was equipped with a custom gripping system and oven to allow the direct testing of preforms (which are basically tubular specimens) in a temperature-controlled environment. The experimental protocol included both uniaxial tests and stress relaxation tests. A viscohyperelastic model then is proposed: the hyperelastic Marlow strain energy function is used in conjunction with linear viscoelasticity to introduce time and temperature dependency. The full constitutive law is determined, including coefficients of the Prony's series and constants of the WilliamLandel-Ferry (WLF) equation. The work follows with the implementation of the constitutive law in a finite element simulation of the ISBM process, in which an axisymmetric model was created with real mould, rod and preform geometries, including ribs and small diameter changes which are typical of modern bottles. A non-uniform temperature of the preform was also considered as this is one of the most crucial process parameters (Chung, 1989; Daver and Demirel, 2012; Demirel and Daver, 2012; Pham et al., 2004; Yang et al., 2014, 2004a).

We then describe the experimental setup, the theoretical framework, the procedure to determine the necessary material constants, and the finite element implementation of the ISBM process. Finally, ISBM simulation results and limitations are discussed with possible future developments of the current approach.

\section{MATERIAL AND METHODS}

\subsection{Preform material and specimen}

Most of the current literature considers virgin PET material samples (Chevalier et al., 2012; Luo et al., 2013; Pham et al., 2004) but this does not allow taking into consideration modifications of the mechanical behaviour caused by the preforming process. All our specimens were obtained directly from the preforms to get a more accurate evaluation of the material that undergoes the ISBM process. PET preforms were made available by Smilab S.r.l. directly from a bottle producer. The preforms were supplied in the exact same condition as they would be during the bottle manufacturing process. There exist different grades of PET, and as reference, for water bottle grade the intrinsic viscosity is often in the range $0.70-0.78 \mathrm{dl} / \mathrm{g}$ (Gupta and Bashir, 2002). In our case, the PET resin was a virgin crystalline PET grade resin with an intrinsic viscosity of $0.80 \pm 0.02 \mathrm{dl} / \mathrm{g}$ (ISO 1628 test method) but the details of preform preparation and other material properties could not be disclosed. The dimensions and a representative image of the studied 
preform are shown in Fig.2.

Tubular samples were obtained by cutting away both the ends of the preforms and keeping the central part. Approximately 45-50 $\mathrm{mm}$ were cut from the top and 20-25 $\mathrm{mm}$ were cut from the bottom of the preform, thus resulting in a sample with the following dimensions: $50 \mathrm{~mm}$ length, $17.17 \mathrm{~mm}$ average inner diameter (considering the conical angle of $0.63^{\circ}$ ), $2.87 \mathrm{~mm}$ wall thickness. Therefore, the crosssectional area for nominal stress calculation was roughly $180.7 \mathrm{~mm}^{2}$.

\subsection{Test equipment and procedures}

The direct testing of preforms allowed investigating the mechanical response of PET in a microstructural condition which was effectively representative of the initial material state. However, this testing methodology also introduced some problems related to the shape of the specimen, which resulted being tubular and slightly conical. For this reason, a dedicated gripping system had to be designed and a special oven was also built. The system, mounted on a servo-hydraulic test machine Instron 8501 as shown in Fig.3, includes an axial load cell with a low nominal load of $10 \mathrm{kN}$ and a thermocouple in contact with the internal wall of the specimen, used to track its temperature during the tests.

Since the conical angle of the wall of the specimens was very small, the nominal stress was calculated with the assumption of the applied force acting normally to the average cross-section. The nominal strain was calculated from the crosshead displacement.

Tensile and compressive tests were carried out up to large deformations (i.e. $300 \%$ ), at different strain rates $\left(1.2\right.$ to $2.7 \mathrm{~s}-1$ ) and with temperatures ranging from $85{ }^{\circ} \mathrm{C}$ to $98{ }^{\circ} \mathrm{C}$ (corresponding to the temperature of most of the preform volume during ISBM).

Stress relaxation tests were also performed to evaluate the viscoelastic properties of PET. During these tests, a small deformation of about $2 \%$ was applied and kept constant for three hours. A value of $85^{\circ} \mathrm{C}$ was chosen as reference temperature and four other temperature levels were considered to define the master curve. In this regard, the viscoelasticity was assumed being linear and the time-temperature superposition principle was assumed being valid.

\subsection{Constitutive modelling approach}

As already mentioned, our constitutive modelling approach for PET during ISBM consisted of a hyperelastic model (Marlow type) enriched with linear viscoelasticity, by means of a Prony series (time dependency) and the William-Landel-Ferry (WLF) equation (temperature dependency), similarly to the material modelling followed in (Battini et al., 2018; Pandini et al., 2016).

Since PET was expected to exhibit significant nonlinearity for the range of temperatures and strain rates under investigation, hyperelasticity provided the necessary framework to account for this type of stressstrain response. A phenomenological approach was adopted, and strain energy functions implemented in several commercial FEM codes, such as Mooney-Rivlin, Yeoh or Ogden type, were taken into consideration. However, in presence of marked softening at lower strains and hardening at higher strains, it can be difficult to suitably fit experimental data. In fact, all these models may become numerically unstable above a limited strain range, causing convergence problems in the simulations. Since the ISBM process leads to very high stretches, using a material model that grants stability for moderate strain levels only is not acceptable.

All this considered, assuming a Marlow (Marlow, 2003) model which is known for being completely determined by a single test [20], was found to be a convenient way to perfectly reproduce the stressstrain response of uniaxial tests at any temperature or strain rate. Although multi-parameters models can be more accurate when data are available for different deformation modes, Marlow model does not require a curve-fitting process and it is also able to adequately simulate the behaviour of the material 
beyond the range of deformation tested, preventing instability in finite element simulations.

Since during the ISBM process PET is stretched at non-uniform high temperatures and strain rates, the hyperelastic response must be coupled with a viscous behaviour to take into consideration time and temperature dependency of the material. With this aim, stress relaxation test data at different temperatures were used to determine the master curve for a reference temperature of $85^{\circ} \mathrm{C}$ by calculating the required shift factors $a_{T}$. In particular, since ISBM is a very fast process (strain rates up to $30 / \mathrm{s}^{-1}$ or more) (Menary et al., 2012) at very high temperature (even over $100^{\circ} \mathrm{C}$ ), tests at temperatures of 65,70 and $75^{\circ} \mathrm{C}$ were used to build the part of the master curve associated with shorter times.

The linear viscoelastic behaviour is then coupled with hyperelasticity via a relaxation function for the shear modulus $\mathrm{G}(\mathrm{t})$, represented with a Prony series as per eq. (1):

$G(t)=G_{0}\left(1-\sum_{i=1}^{N} g_{i} e^{-t / \tau_{i}}\right)$

The coefficient pairs $\left(g_{i}, \tau_{i}\right)$ were calculated from the master curve with a nonlinear least squares fitting method with the time parameters $\tau_{i}$ being forced to range over all the time spectrum of the master curve. $G_{0}$ is the instantaneous shear modulus, with an estimated value of $850 \mathrm{MPa}$. The shift factors $a_{T}$ that were calculated to obtain the master curve were used to fit the Williams-Landel-Ferry equation as reported below in eq. (2):

$\log \left(a_{T}\right)=\frac{-C_{1}\left(T-T_{0}\right)}{C_{2}+\left(T-T_{0}\right)}$

where $C_{1}$ is a dimensionless coefficient, $C_{2}$ is a coefficient with dimensions of temperature, $T_{0}$ is the reference temperature $\left(85^{\circ} \mathrm{C}\right)$ and $T$ is the stress-relaxation testing temperature used for the application of the time-temperature superposition principle.

\subsection{Finite Element Model of ISBM}

A FEM model of ISBM was implemented using the code Simulia Abaqus v6.14, under the assumption of axial symmetry. The explicit solver was chosen due to the high deformation, the high strain rates and the complex contact interactions between the preform, the rod and the mould.

The model reproduces the two main phases of ISBM: in the first one, called pre-blow, the stretch rod moves down very fast ( $2 \mathrm{~m} / \mathrm{s}$ ) while an initial pressure of 3 bar is applied inside the preform. In the second phase, called final-blow, the stretch rod has already reached the end of the mould (causing the preform to be fully stretched along the axial direction) and the inner pressure is increased to 36 bar to complete the bottle shape by forcing the preform against the mould walls (Fig.4). Temperature measurements were carried out on the preforms with a thermographic camera just before ISBM process in order to catch the real temperature distribution of the preform at the beginning of the process. The temperature distribution was applied to the FEM model via predefined volume field as shown in Fig.5. The upper part of the preform is physically blocked by the machine during the process, and so is in the FEM model, where the top section is blocked along the axial and radial direction to react to the stretch rod movement and the blowing pressure. In addition, a small (fictitious) viscous pressure is applied on the external surface of the preform to help preventing numerical instabilities possibly associated with the use of an explicit solver. The viscous pressure is a surface load with a direct dependency on the velocity field (therefore the term "viscous"). This type of surface load is usually very small and ends up being convenient with the explicit solver since it enhances the numerical stability of the simulation by damping sudden displacements or high-frequency vibrations of critical nodes/elements. This load acts as pure numerical damping, but it must be noted that results were not affected since the energy associated with 
the viscous pressure was negligible compared to any other physically-meaningful energy. For better understanding, boundary conditions and external loads are reported in Fig.6.

The rod consists of a cylinder (10 mm diameter) with a semi-spherical ending at the bottom and it is modelled as a rigid moving part with 36 rigid axisymmetric elements (RAX2). The 2D profile of the mould is obtained directly from the 3D geometry of a real bottle design (Fig. 7), including the presence of ribs. The mould is modelled as an analytical rigid surface. The main dimensions of the preform are reported in Fig.2.

In the model, a region of about $17 \mathrm{~mm}$ axial length is removed from the top of the preform as it does not undergo any deformation during the ISBM process. The preform is the only deformable part in the simulation and its mechanical response was modelled as previously described in paragraph 2.3. In our scenario, the material of the preform was considered being perfectly incompressible (therefore, with a Poisson coefficient $v$ of 0.5 ). The perfect incompressibility assumption of the material for this simulation was also investigated with sensitivity analyses. Specifically, we repeated the ISBM process simulation starting with a Poisson's coefficient ( $v$ ) value of 0.5 and going down to $v=0.44$ which is a reasonable value for PET material. Even though the preform undergoes huge stretches, the transient and the ending results of such analyses showed negligible sensitivity to compressibility variations, probably due to the material not being highly confined. The preform part is meshed with 6630 linear quadrilateral axisymmetric elements (CAX4R) with 6 elements along the thickness of the preform to catch eventual stress gradients. Since ISBM causes huge stretches on the preform, with a ratio of $\approx 15: 1$ between undeformed and deformed thickness, the mesh was set up to avoid the use of remeshing procedures while still limiting excessive element distortion. For this reason, the initial length of the elements along the stretching axis is very small compared to the length along the thickness (see Fig 6). Contact interactions are modelled using the surface-to-surface algorithm for both the rod-preform pair and mould-preform pair, with the preform always being the slave surface. A friction coefficient of 0.3 was also assumed for both interactions.

\section{RESULTS AND DISCUSSION}

\subsection{Experimental stress-strain curves}

Experimental data of the nominal stress-strain curves at different strain rates and temperatures are reported in Fig. 8 and Fig. 9, respectively.

As expected, the behaviour of the material was highly non-linear, with an initially stiffer response, followed by flow and strain hardening at higher strain level. Overall, the response observed for the material in the preform condition is consistent with findings reported in literature for PET samples under different loading conditions. In particular, in (Boyce et al., 2000) four basic features were observed for the stress-strain behaviour of PET samples under uniaxial compression and planar strain compression: a relatively stiff initial response, followed by a rollover to flow and then a steady increase in the stress with strain ("initial strain hardening") followed by a marked increase in stress with strain at very large strains ("dramatic hardening" region). Each one of these features was also reported to depend on the strain rate and the temperature. Similarly, the stress-strain curves obtained in (Gough et al., 1999) for tensile tests of PET at different temperatures showed that the stress increases gradually at first and then rapidly rises up. In (Menary et al., 2012) a highly nonlinear stress-strain response was also observed for PET biaxial deformation, but with a pronounced strain hardening only above $100 \%$ nominal strain.

As already mentioned, in order to evaluate strain rate sensitivity of our PET preform, a reference temperature of $95^{\circ} \mathrm{C}$ was considered to compare tests at strain rates in the range of 1.2 to $2.7 \mathrm{~s}^{-1}$ (see Fig.8). Mechanical properties dependency on the strain rate can be clearly appreciated in the form of a 
relatively stiffer response over the whole strain range under investigation at higher strain rates. Considering literature, in (Boyce et al., 2000) the basic features (previously described) of PET mechanical response were reported to exhibit different degrees of dependence on the strain rate. While the initial stiffness exhibited a negligible dependence, increasingly higher dependence was reported for the other three features: the stress level for rollover to flow, the initial hardening slope and the strain at which the transition to dramatic hardening takes place. In particular, lower strain rates (longer times) were found to delay the rise in the stress-strain curve, which is again consistent with the findings of the present work. In (Menary et al., 2012), the overall stress level was also found to increase with increasing strain rate on equi-biaxial stretching tests of PET samples. This effect is also observed on the preform under investigation due to the presence of two concurrent phenomena leading to higher stress levels at higher strain rates: the elastic component of the polymer has a faster response than the viscous component, and the time available for the relaxation processes decreases.

The effect of a temperature increase on the stress-strain response of PET preform is shown in Fig.9. As expected, compared to increasing the strain rate, the opposite effect is noticeable and higher temperatures result in a softening of the material. By comparison, in (Boyce et al., 2000), the initial stiffness and all the strain hardening phenomena showed a strong temperature dependency for tests at 90,100 , and $105^{\circ} \mathrm{C}$. In fact, a small change of the temperature of the material caused significant changes in its mechanical behaviour and its underlying microstructure. In (Gough et al., 1999), for tensile testing, the onset of the strain hardening resulted being delayed toward higher strains by a temperature increase and no strain hardening occurred at the temperature of $105^{\circ} \mathrm{C}$ under the employed stretch strain. Biaxial tests were carried out in (Menary et al., 2012) and the modulus, the yield stress, the flow stress and the strain hardening stress all decreased as the temperature increased. Inversely to strain rate effects, a temperature increase causes the onset of strain hardening to occur at a higher deformation level due to the relaxation processes being facilitated by higher temperatures. However, the influence of strain rate on the onset of strain hardening is less noticeable, except for very high temperatures when chain orientation phenomena are dominant at lower strain rates.

\subsection{Stress-relaxation tests}

The results obtained from stress-relaxation tests are reported in Fig.10 and a significant stress-relaxation effect can be observed for the range of temperatures we investigated. Based on stress-relaxation tests data, the partial master curve was reconstructed assuming a reference temperature $T_{0}$ of $85{ }^{\circ} \mathrm{C}$ as shown in Fig. 11. Under the assumption of the time-temperature superposition principle being valid, the partial master curve was obtained by calculating the appropriate shift factors associated with each $\Delta T=T_{\text {test }}-$ $T_{r e f}$ in order to get a continuous curve. Therefore, a negative $\Delta T$ causes a shift towards shorter times while a positive $\Delta T$ shifts towards longer times instead. An instantaneous hyperelastic uniaxial stressstrain response was also extrapolated from uniaxial and stress-relaxation data, as it was a required input for the FE software.

All the pairs $\left(\tau_{i}, g_{i}\right)$ used to fit the master curve of Fig. 11 are reported in Table 1 . William-Landel-Ferry coefficients were obtained with a nonlinear least squares fitting and resulted: $C_{1}=10.6, C_{2}=61.8{ }^{\circ} \mathrm{C}$. These data were then used as input for the visco-hyperelastic constitutive law adopted in the FEM model.

\subsection{Biaxial stress-strain curves from FE simulations}

As already pointed out, a common approach for PET characterization is to perform biaxial stretching experiments in which thin PET sheets are loaded biaxially under defined variations of temperature, strain rate and deformation mode. In the present work, we proposed an alternative approach which is essentially 
based on uniaxial tests on a preform. Both approaches have pros and cons. Considering biaxial tests, as pointed out in (Zimmer and Stommel, 2013): "these experiments include process simplifications regarding geometry, heating and deformation parameters. The production of PET sheets could imply different internal stresses compared to the preforms due to different shear loadings during injection moulding". Uniaxial tests on preforms provide instead information concerning a material condition closer to the industrial process to be simulated but do not allow the investigation of multiaxial loading modes that may be present during inflation.

For preliminary comparison purposes some finite element simulations of an equibiaxial test campaign were carried out. These virtual tests were performed with our material model and with the same strain rates and temperature commonly applied in literature (i.e. (Chevalier et al., 2012; Menary et al., 2012)). Results are reported in Fig. 12 with two charts representing different conditions: on the left a fixed temperature of $100^{\circ} \mathrm{C}$ with 6 different strain rates (from $1 \mathrm{~s}^{-1}$ to $32 \mathrm{~s}^{-1}$ ) and on the right a fixed strain rate of $1 \mathrm{~s}^{-1}$ with 5 different temperatures (from $90^{\circ} \mathrm{C}$ to $110^{\circ} \mathrm{C}$ ).

Overall, the predicted biaxial stress-strain curves exhibit the same trends of data reported in (Chevalier et al., 2012; Menary et al., 2012) with a strong dependency on both the strain rate and the temperature. On the other hand, a noticeable difference is that the transition from plateau to stiffer behaviour occurs, in our case, at a lower strain level compared to experimental equibiaxial tests (i.e. 0.95-1 vs 1.5) carried out in literature (Chevalier et al., 2012; Menary et al., 2012). However, it must be noted that drawing conclusions from this comparison is not straightforward. In fact, it is hard to conclude whether this difference is only caused by using the preform over more common moulded samples or it is caused by some limitations in the model, which is actually fitted on a different stress state. For this reason, and in agreement with the bottle producer company, we considered the comparison between predicted and measured thickness distribution in the bottle more significant.

\subsection{ISBM FEM Model}

\subsubsection{Preform deformation}

Fig.13 shows the predicted preform evolution during the ISBM process by reporting the contour map of the maximum nominal strain at different times. The time history of the deformed shape is really interesting and, as expected, it shows a high sensitivity to the two most important process parameters (besides material temperature of course): the motion law of the stretch rod and the blowing pressure (Chung, 1989; Daver and Demirel, 2012; Gough et al., 1999; Huang et al., 2007; Menary et al., 2000). Specifically, the time offset between the end of the stretch rod movement and the start of the pressure ramp from 3 to 36 bar, which was highlighted in Fig.4, is very crucial for a successful ISBM process. Overall, the simulation of the transient phase is considered close to the real evolution of the bottle during the different phases according to the experience of the bottle manufacturer that provided the preform.

Fig. 13 also allows for the identification of the most critical areas of the bottle which resulted in being all the ribs, again as expected. More precisely, the first rib from top to bottom is the one undergoing maximum deformation. Fig.14 shows in detail the maximum principal nominal strain map at the most critical location (first rib from top to bottom, point A in Fig.15). We can appreciate that at the end of the ISBM process the maximum principal nominal strain exceeds the $400 \%$.

\subsubsection{Thickness of the profile}

The thickness distribution along the profile of the bottle at the end of the process is possibly the most important parameter for the product quality control at manufacturing plant. In order to assess and validate predictive capabilities of the model it is particularly relevant to compare model results and experimental 
measurements at different locations.

The profile of the bottle predicted with our FEM model is represented in Fig. 15, including positions of the points where thickness was compared with experimental evidence for a real bottle of the same geometry and produced with the same process parameters considered in this work.

Results of thickness measurements using a micrometre with a spherical end are reported in Table 2, together with model predictions.

Predicted thickness at point A showed excellent agreement between finite element simulation and experimental data, with a similar trend for a non-uniform thickness distribution along the length of the bottle. On the other hand, it should be noted that point B and C showed relatively smaller thickness in the FEM simulation compared to the experimental test. Considering the number of process parameters involved, understanding the possible causes of such discrepancies is not easy. In fact, as reported in (Salomeia et al., 2013), changes of preform temperature, mass flow rate or blowing kinematics may affect thickness in the different regions of the final bottle. More specifically, for what concerns the present study, a crucial point is certainly the definition of temperature profile, since heat exchange was not directly modelled, and some simplifying assumptions were considered. In particular, the effects related to heating were introduced by assigning to the preform a predefined initial temperature distribution. As could be observed in Fig. 16, the temperature field changes along the bottle length and follows the deformation of the bottle during the simulation of the ISBM process.

This kind of temperature distribution is quite typical for a PET preform undergoing ISBM process (Chung, 1989; Daver and Demirel, 2012; Demirel, 2017; Menary et al., 2000; Pham et al., 2004; Yang et al., 2014). Once the bottle is fully formed, after the final-blow phase and before removing the internal pressure, the temperature lowers below $40^{\circ} \mathrm{C}$ preventing huge spring back phenomena and thus "freezing" the deformed shape of the preform.

Accordingly, in our simulation the preform cools to room temperature only during the final stages of the ISBM process, when the bottle is already fully shaped, assuming an almost instantaneous "freezing" effect of the material when contact with the mould occurs. This approach, in which heat transfer is not directly simulated, is similar to other works (Chung, 1989; Daver and Demirel, 2012; Demirel and Daver, 2012; Pham et al., 2004; Yang et al., 2004b, 2004a), because magnitude and rate of heat transfer are currently largely unknown (Yang et al., 2014). Moreover, heat exchange modelling would still be quite a challenging task as shown in (Luo et al., 2015) where Luo et al. discussed a simplified approach for heat transfer modelling on preforms. However, it must be noted that in the real process huge heat dissipation phenomena occur as the preform comes into contact with the mould. Therefore, the temperature distribution of the preform could be affected by the different times at which this contact occurs in different bottle locations and may explain the differences observed in thickness distribution. In order to check this hypothesis, we took into consideration thickness values predicted by the simulation as soon as the respective location comes into contact with the mould (i.e. each value is measured in a different instant as each point comes into contact with the mould at a different time). As reported in Table. 2 in this case a better agreement with experimental data can be noticed. This indicates that by including thermal interactions in the simulation, result accuracy could improve.

\section{CONCLUSIONS}

In this article, we presented an innovative approach for the characterization of PET in relation to the ISBM process commonly used in bottles production. Virgin material is usually tested in the current literature, due to the possibility of creating suitable samples for common testing (uniaxial and biaxial tests). However, preforms used in the injection stretch blow moulding undergo thermo-mechanical processes that modify their shape and properties. Since the ISBM process is very complex and material 
properties modification might be crucial for its understanding, we developed a specific apparatus to directly test preforms on a standard servo-hydraulic uniaxial testing machine. A specific gripping system and oven were designed to guarantee a good handle and to control the temperature of the samples during the tests. A Marlow-type strain energy function enriched with a Prony series and William-Landel-Ferry equation were chosen to describe the visco-hyperelastic behaviour of PET. This choice allowed representing time and temperature dependency as well as a highly nonlinear stress-strain response. The constitutive law was implemented in a finite element simulation to investigate the possibility of accurately modelling the ISBM process. The simulation led to a realistic formed shape of the final bottle, with good agreement between numeric and experimental measurements of wall thickness. In the end, even though parametric studies have still to be carried out, simulation setup and results highlighted the crucial role of stretch rod motion law, inflation pressure law and their interaction as it was to be expected. Finite element simulations can be helpful to shorten the trial and error approach typically used for the optimization of all the crucial process parameters: bottle geometry and material, temperature, stretch rod motion law and blowing pressure law.

\section{REFERENCES}

Adams, A.M., Buckley, C.P., Jones, D.P., 2000. Biaxial hot drawing of poly(ethylene terephthalate): measurements and modelling of strain-stiffening. Polymer (Guildf). 41, 771-786.

https://doi.org/10.1016/S0032-3861(98)00834-9

Avanzini, A., Gallina, D., 2011. Effect of Cyclic Strain on the Mechanical Behavior of a Thermoplastic Polyurethane. J. Eng. Mater. Technol. 133, 021005. https://doi.org/10.1115/1.4003101

Awaja, F., Pavel, D., 2005. Injection stretch blow moulding process of reactive extruded recycled PET and virgin PET blends. Eur. Polym. J. 41, 2614-2634.

https://doi.org/10.1016/j.eurpolymj.2005.05.036

Battini, D., Donzella, G., Avanzini, A., Zenoni, A., Ferrari, M., Donzella, A., Pandini, S., Bignotti, F., Andrighetto, A., Monetti, A., 2018. Experimental testing and numerical simulations for life prediction of gate valve O-rings exposed to mixed neutron and gamma fields. Mater. Des. 156, 514-527. https://doi.org/10.1016/j.matdes.2018.07.020

Billon, N., Picard, M., Gorlier, E., 2014. Stretch blow moulding of PET; structure development and constitutive model. Int. J. Mater. Form. 7, 369-378. https://doi.org/10.1007/s12289-013-1131-1

Boyce, M.C., Socrate, S., Llana, P.G., 2000. Constitutive Model for the Finite Deformation StressStrain Behavior of Poly(ethylene Terephthalate) Above the Glass Transition. Polymer (Guildf). 41, 2183-2201. https://doi.org/10.1016/S0032-3861(99)00406-1

Buckley, C.P., 1995. Glass-rubber constitutive model for amorphous polymers near the glass transition. Polymer (Guildf). 36, 3301-3312. https://doi.org/10.1016/0032-3861(95)99429-X

Chevalier, L., Luo, Y.M., Monteiro, E., Menary, G.H., 2012. On visco-elastic modelling of polyethylene terephthalate behaviour during multiaxial elongations slightly over the glass transition temperature. Mech. Mater. 52, 103-116. https://doi.org/10.1016/j.mechmat.2012.05.003

Chung, K., 1989. Finite element simulation of pet stretch/blowmolding process. J. Mater. Shap. Technol. 7, 229-239. https://doi.org/10.1007/BF02834774

Cosson, B., Chevalier, L., Régnier, G., 2012. Simulation of the stretch blow moulding process: from the modelling of the microstructure evolution to the end-use elastic properties of polyethylene terephthalate bottles. Int. J. Mater. Form. 5, 39-53. https://doi.org/10.1007/s12289-010-1010-y

Cosson, B., Chevalier, L., Yvonnet, J., 2008. Optimization by the C-NEM Method of the Stretch-Blow Molding Process of a PET Bottle Near T g. Int. J. Mater. Form. 1, 707-710. 
https://doi.org/10.1007/s12289-008-0313-8

Daver, F., Demirel, B., 2012. A simulation study of the effect of preform cooling time in injection stretch blow molding. J. Mater. Process. Technol. 212, 2400-2405.

https://doi.org/10.1016/j.jmatprotec.2012.06.004

Demirel, B., 2017. Optimisation of mould surface temperature and bottle residence time in mould for the carbonated soft drink PET containers. Polym. Test. 60, 220-228. https://doi.org/10.1016/J.POLYMERTESTING.2017.03.030

Demirel, B., Daver, F., 2012. Effects of preform deformation behavior on the properties of the poly(ethylene terephthalate) bottles. J. Appl. Polym. Sci. 126, 1300-1306. https://doi.org/10.1002/app.36925

Fu, Y.B., Ogden, R.W., 2001. Nonlinear elasticity: Theory and Applications. Cambridge University Press. https://doi.org/https://doi.org/10.1017/CBO9780511526466

Gough, J., H., G.I., Muhr, A.H., 1999. Determination of constitutive equations for vulcanized rubber, in: Finite Element Analysis of Elastomers. Professional Engineering Publishing, London, pp. 526.

Gupta, S., Uday, V., Raghuwanshi, A.S., Chowkshey, S., Das, S.N., Suresh, S., 2013. Simulation of Blow Molding Using Ansys Polyflow. APCBEE Procedia 5, 468-473. https://doi.org/10.1016/j.apcbee.2013.05.079

Gupta, V.B., Bashir, Z., 2002. Handbook of Thermoplastic Polyesters, in: Handbook of Thermoplastic Polyester. WILEY-VCH Verlag GmbH \& Co. KGaA.

Holzapfel, G.A., 2000. Nonlinear Solid Mechanics: A Continuum Approach for Engineering. WILEYVCH Verlag GmbH \& Co. KGaA.

Huang, H.-X., Yin, Z.-S., Liu, J.-H., 2007. Visualization study and analysis on preform growth in polyethylene terephthalate stretch blow molding. J. Appl. Polym. Sci. 103, 564-573. https://doi.org/10.1002/app.25116

Luo, Y.-M., Chevalier, L., Monteiro, E., 2016. An anisotropic visco-hyperelastic model for PET behavior under ISBM process conditions. p. 020003. https://doi.org/10.1063/1.4963407

Luo, Y.-M.M., Chevalier, L., Utheza, F., Monteiro, E., 2013. Numerical simulation of the thermodependant viscohyperelastic behavior of polyethylene terephthalate near the glass transition temperature: Prediction of the self-heating during biaxial tension test. Polym. Eng. Sci. 53, 26832695. https://doi.org/10.1002/pen.23522

Luo, Y.M., Chevalier, L., Utheza, F., Nicolas, X., 2015. Simplified Modeling of Convection and Radiation Heat Transfer during Infrared Heating of PET Sheets and Preforms. Int. Polym. Process. 30, 554-565. https://doi.org/10.3139/217.3092

Marlow, R.S., 2003. A general first Invariant hyperelastic constitutive model, in: Muhr, B.\& (Ed.), Constitutive Models for Rubber III. Swets \& Zeitlinger.

Menary, G.H., Armstrong, C.G., Crawford, R.J., McEvoy, J.P., 2000. Modelling of poly(ethylene terephthalate) in injection stretch-blow moulding. Plast. Rubber Compos. 29.

Menary, G.H., Tan, C.W., Harkin-Jones, E.M.A., Armstrong, C.G., Martin, P.J., 2012. Biaxial deformation and experimental study of PET at conditions applicable to stretch blow molding. Polym. Eng. Sci. 52, 671-688. https://doi.org/10.1002/pen.22134

Pandini, S., Avanzini, A., Battini, D., Berardi, M., Baldi, F., Bignotti, F., 2016. Shape memory behavior of epoxy-based model materials: Tailoring approaches and thermo-mechanical modeling, in: AIP Conference Proceedings 1736. AIP Publishing, pp. 020175-1-020175-4. https://doi.org/10.1063/1.4949750

Pham, X.T., Thibault, F., Lim, L.T., 2004. Modeling and simulation of stretch blow molding of polyethylene terephthalate. Polym. Eng. Sci. 44, 1460-1472. https://doi.org/10.1002/pen.20142

Raza, S.H., Soyarslan, C., Bargmann, S., Klusemann, B., 2019. Computational modeling of amorphous 
polymers: A Lagrangian logarithmic strain space formulation of a glass-rubber constitutive model. Comput. Methods Appl. Mech. Eng. 344, 887-909.

https://doi.org/10.1016/J.CMA.2018.10.007

Salomeia, Y.M., Menary, G.H., Armstrong, C.G., 2013. Experimental Investigation of Stretch Blow Molding, Part 2: Analysis of Process Variables, Blowing Kinematics, and Bottle Properties. Adv. Polym. Technol. 32, E436-E450. https://doi.org/10.1002/adv.21291

Schmidt, F.M., Agassant, J.F., Bellet, M., Desoutter, L., 1996. Viscoelastic simulation of PET stretch/blow molding process. J. Nonnewton. Fluid Mech. 64, 19-42. https://doi.org/10.1016/0377-0257(95)01420-9

Tan, C.W., Menary, G.H., Salomeia, Y., Armstrong, C.G., Picard, M., Billon, N., Harkin-Jones, E.M.A., Martin, P.J., Maheshwari, K., 2008. Modelling of the injection stretch blow moulding of PET containers via a Pressure-Volume-time (PV-t) thermodynamic relationship. Int. J. Mater. Form. 1, 799-802. https://doi.org/10.1007/s12289-008-0296-5

Wang, S., Makinouchi, A., Okamoto, M., Kotaka, T., Maeshima, M., Ibe, N., Nakagawa, T., 2000. Viscoplastic Material Modeling for the Stretch Blow Molding Simulation. Int. Polym. Process. 15, 166-175. https://doi.org/10.3139/217.1582

Yan, S., Menary, G., Nixon, J., 2017. A novel methodology to characterize the constitutive behaviour of polyethylene terephthalate for the stretch blow moulding process. Mech. Mater. 104, 93-106. https://doi.org/10.1016/J.MECHMAT.2016.10.006

Yang, Z.J., Harkin-Jones, E., Menary, G.H., Armstrong, C.G., 2004a. A non-isothermal finite element model for injection stretch-blow molding of PET bottles with parametric studies. Polym. Eng. Sci. 44, 1379-1390. https://doi.org/10.1002/pen.20133

Yang, Z.J., Harkin-Jones, E., Menary, G.H., Armstrong, C.G., 2004b. Coupled temperaturedisplacement modelling of injection stretch-blow moulding of PET bottles using Buckley model. J. Mater. Process. Technol. 153-154, 20-27. https://doi.org/10.1016/j.jmatprotec.2004.04.203

Yang, Z.J., Harkin-Jones, E.M.A., Armstrong, C.G., Menary, G.H., 2014. Finite element modelling of stretch-blow moulding of PET bottle using Buckley model: plant tests and effects of process conditions and material parameters. Proc. Inst. Mech. Eng. Part E J. Process Mech. Eng.

Zimmer, J., Stommel, M., 2013. Method for the evaluation of stretch blow molding simulations with free blow trials. IOP Conf. Ser. Mater. Sci. Eng. 48. https://doi.org/10.1088/1757899X/48/1/012004 


\section{FIGURES}

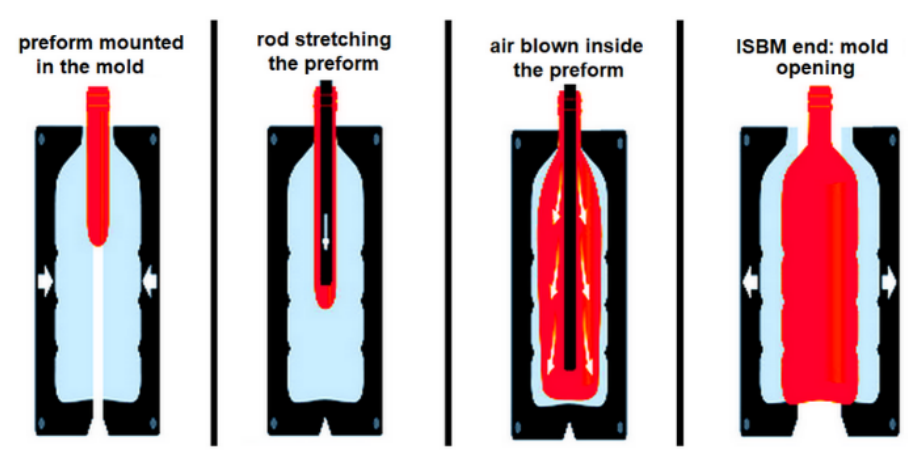

Fig.1 Main steps of ISBM
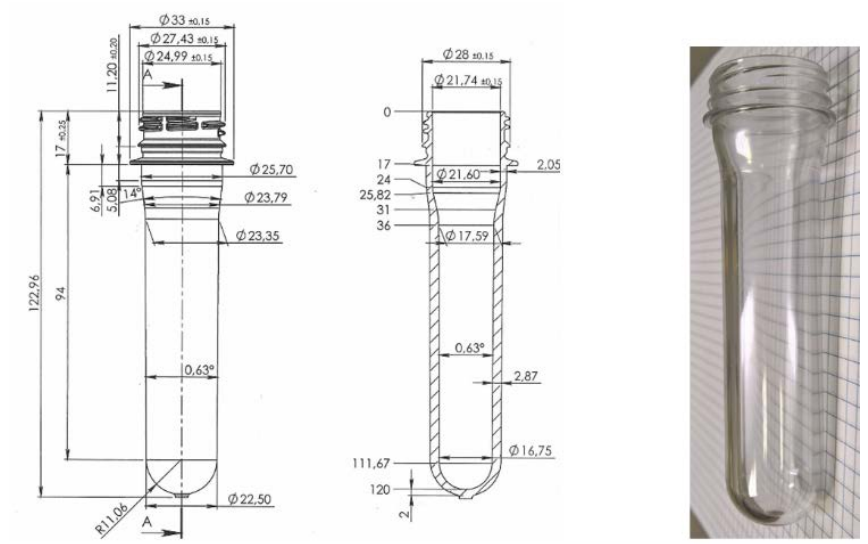

Fig. 2 PET preform dimensions

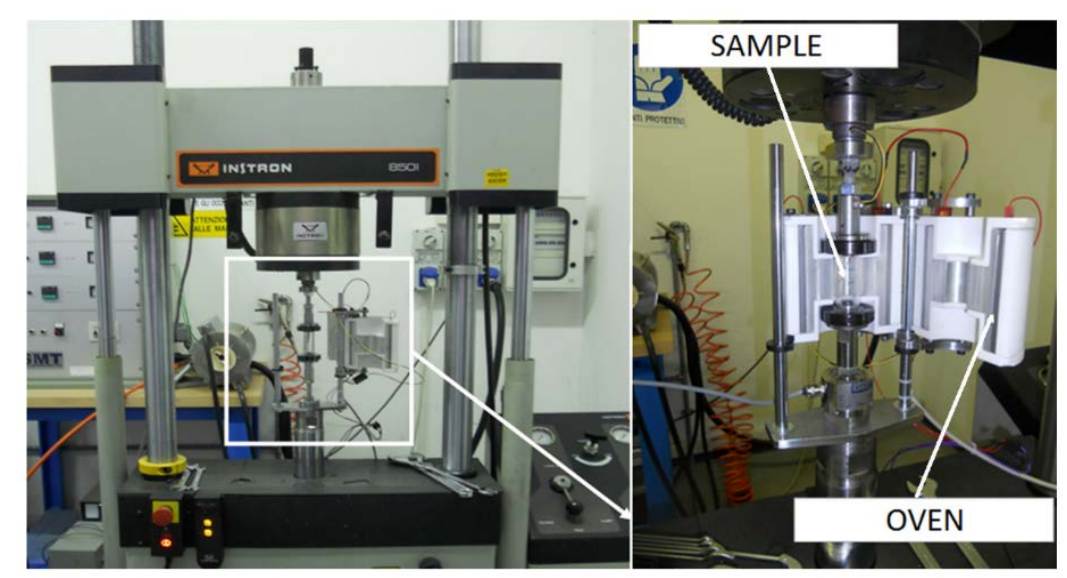

Fig.3 Test machine, gripping system and oven 


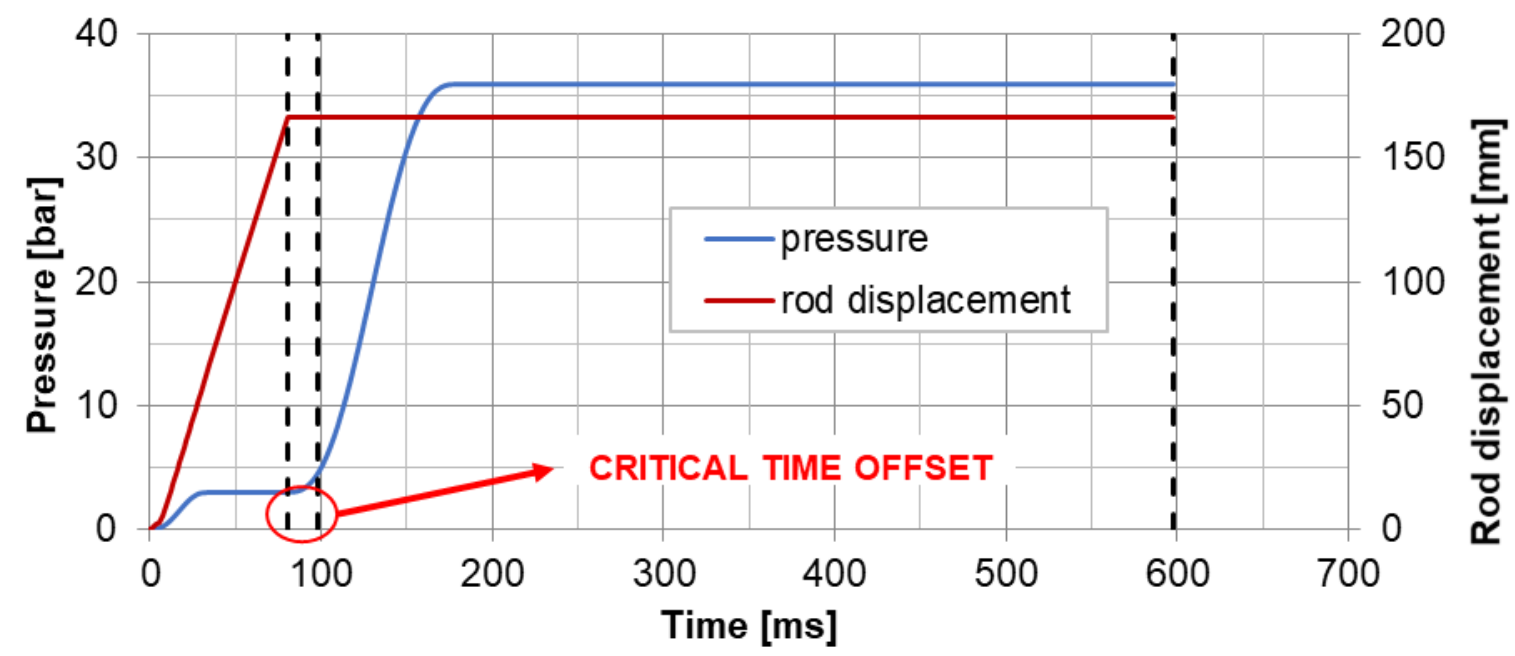

Fig.4 Pressure law and stretch rod motion law for simulation of the ISBM process

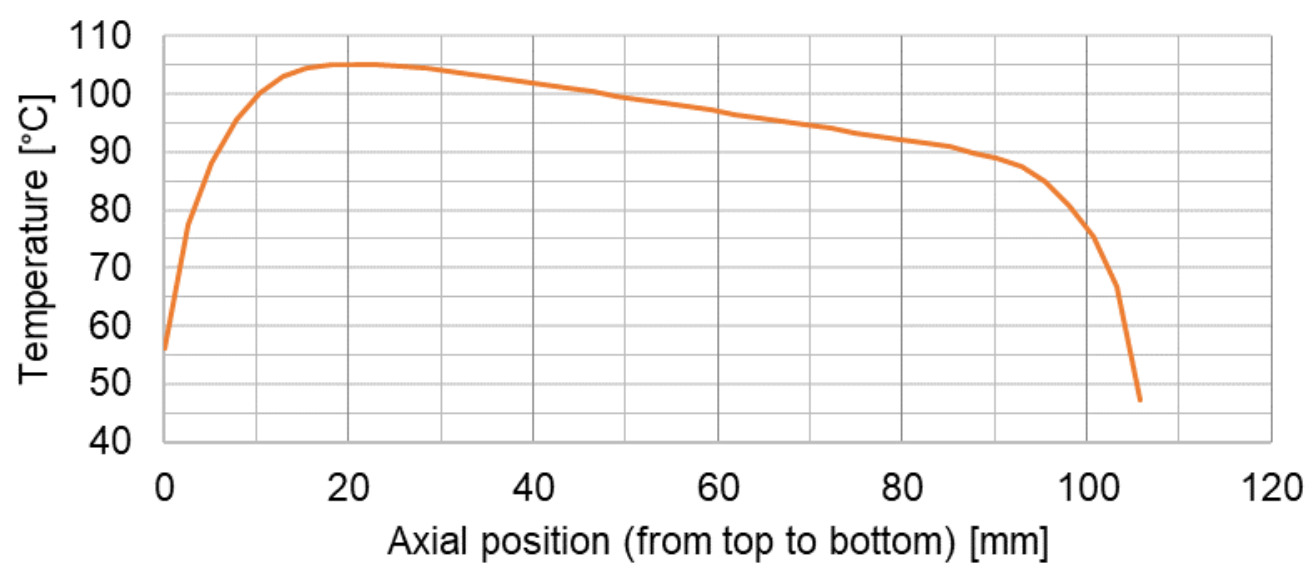

Fig.5 Initial temperature distribution along preform axis (experimental) 


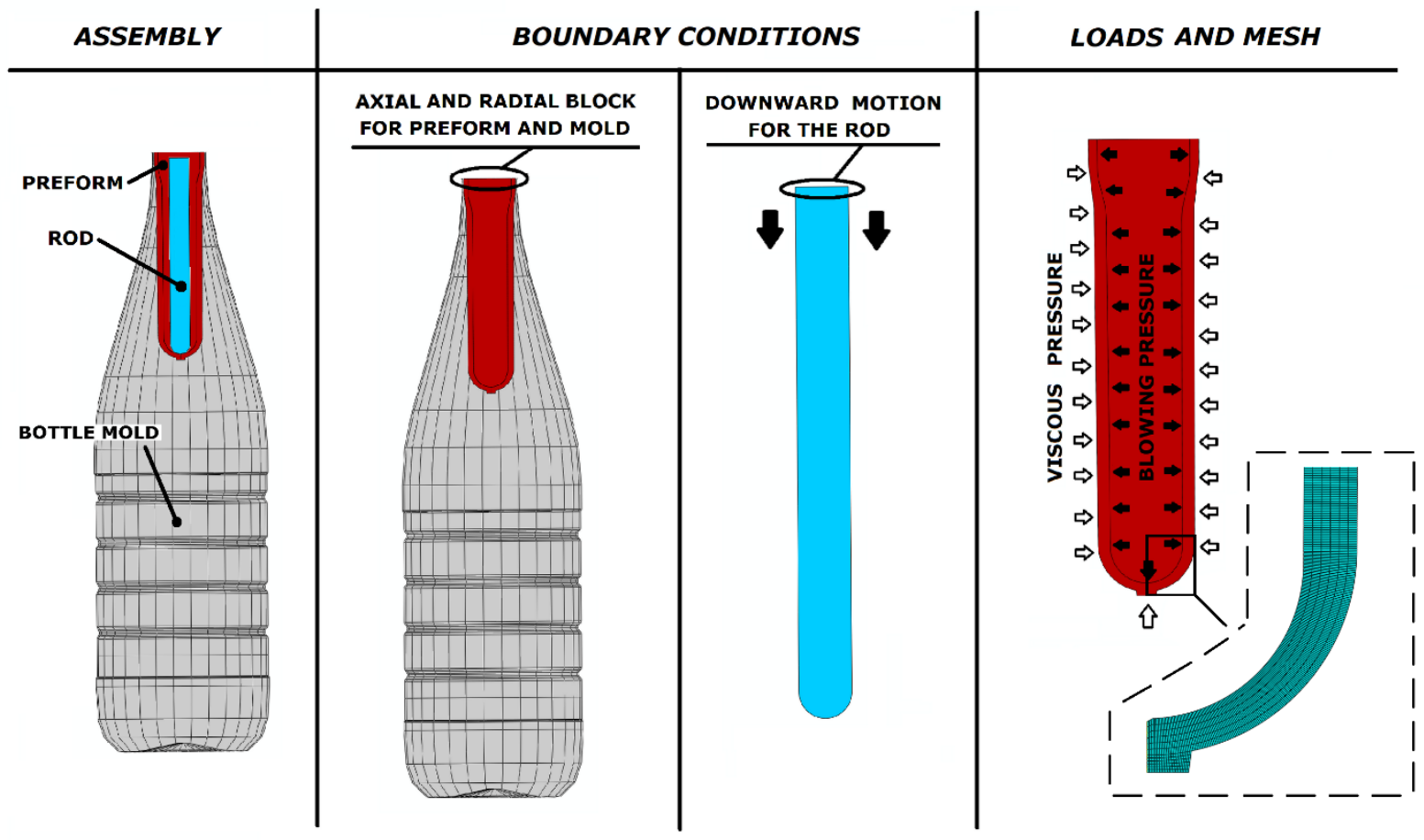

Fig.6 Boundary conditions applied for the FEM simulation of ISBM.

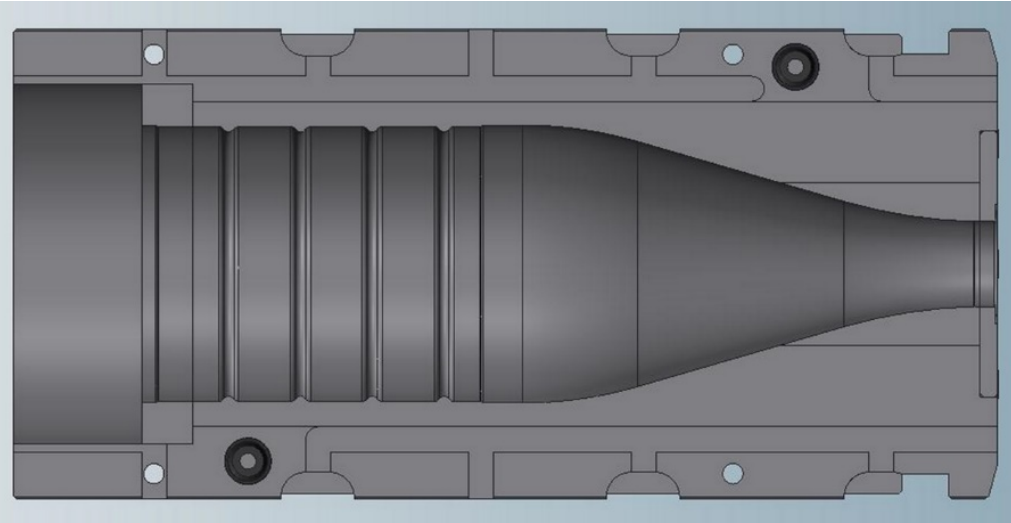

Fig.7 3D geometry of the mould 


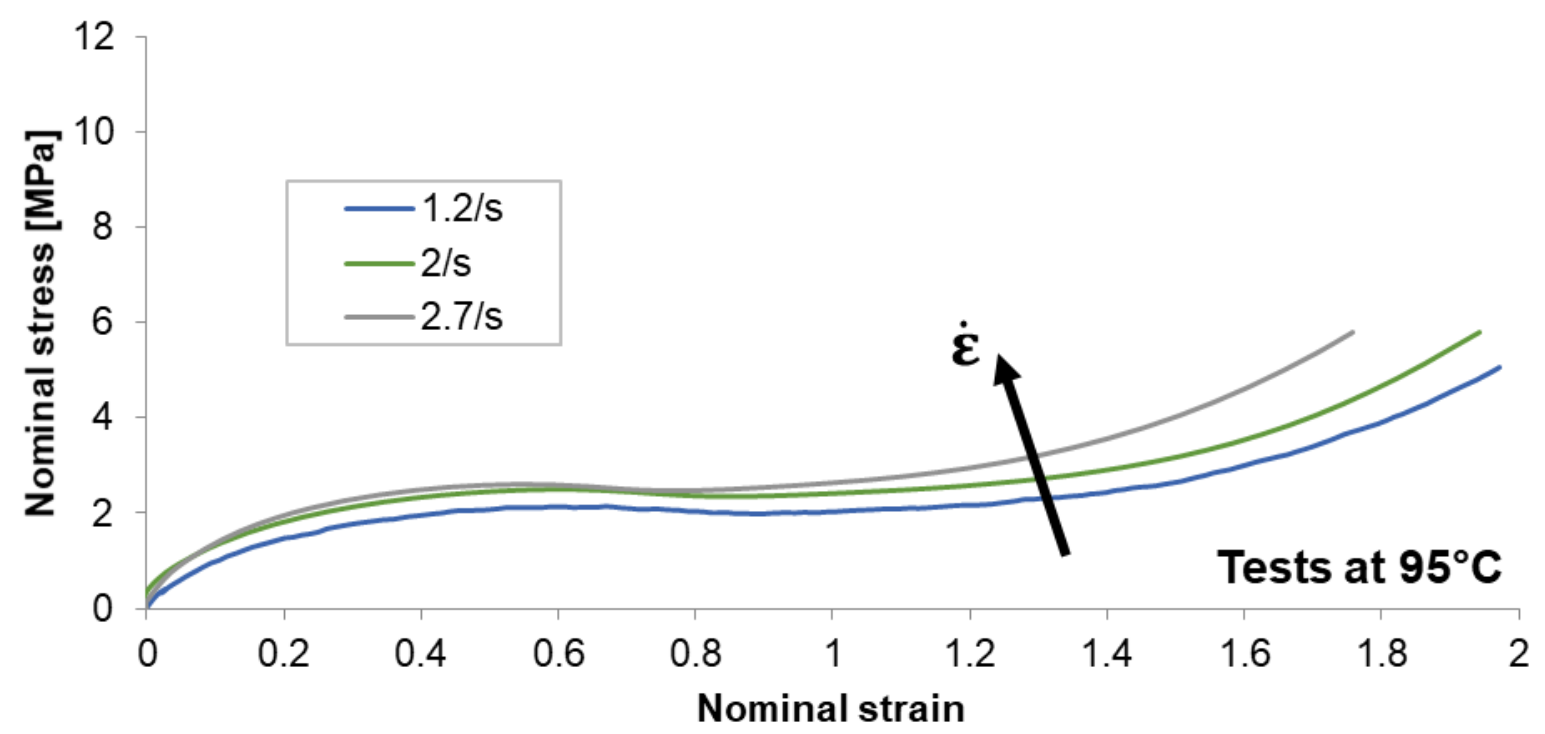

Fig.8 Test at different strain rates

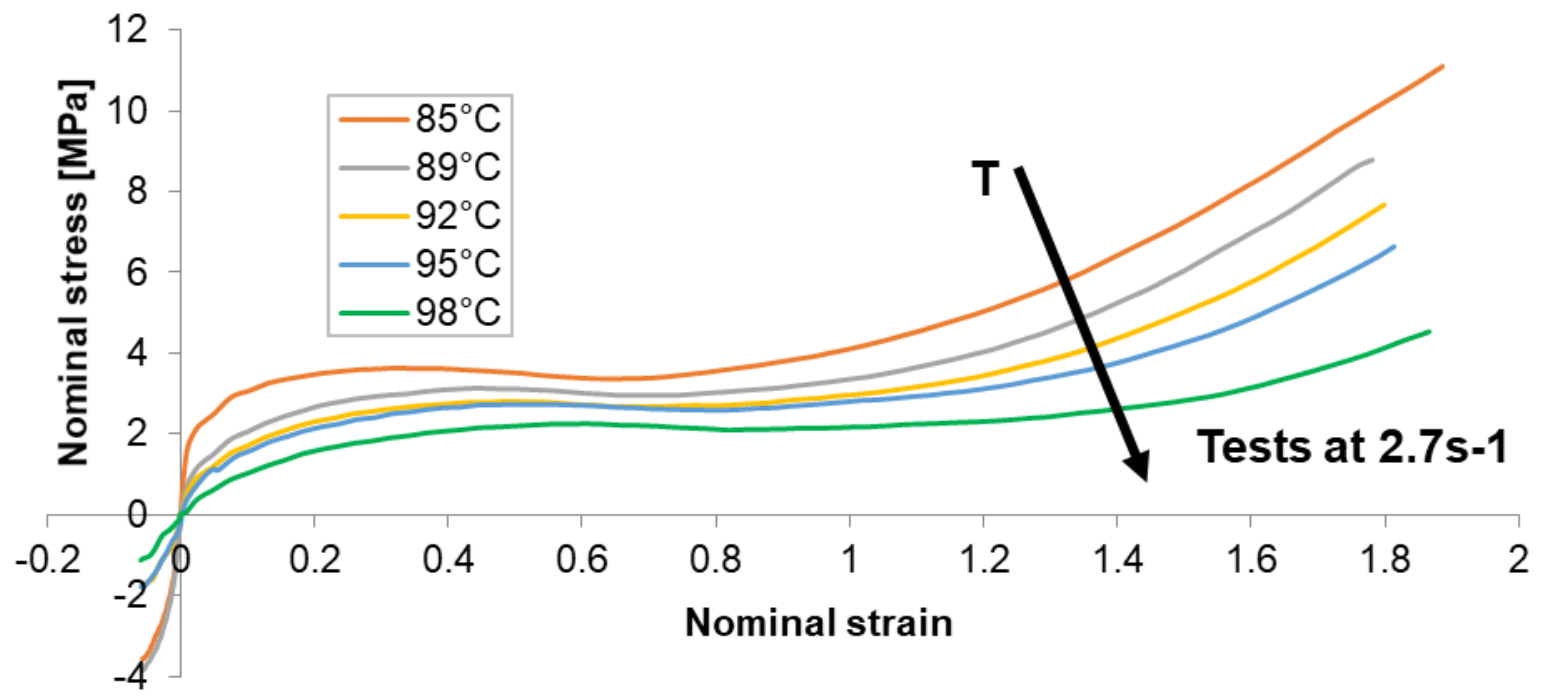

Fig.9 Test at different temperatures 


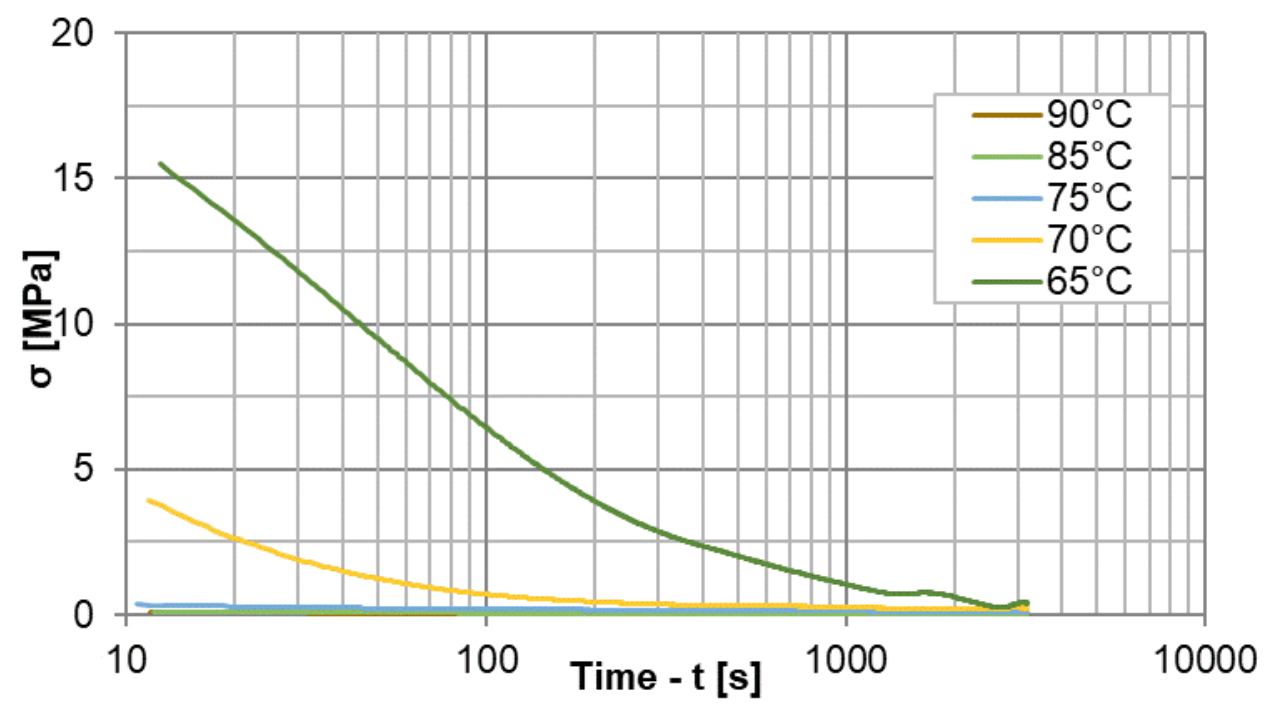

Fig.10 Stress relaxation tests data

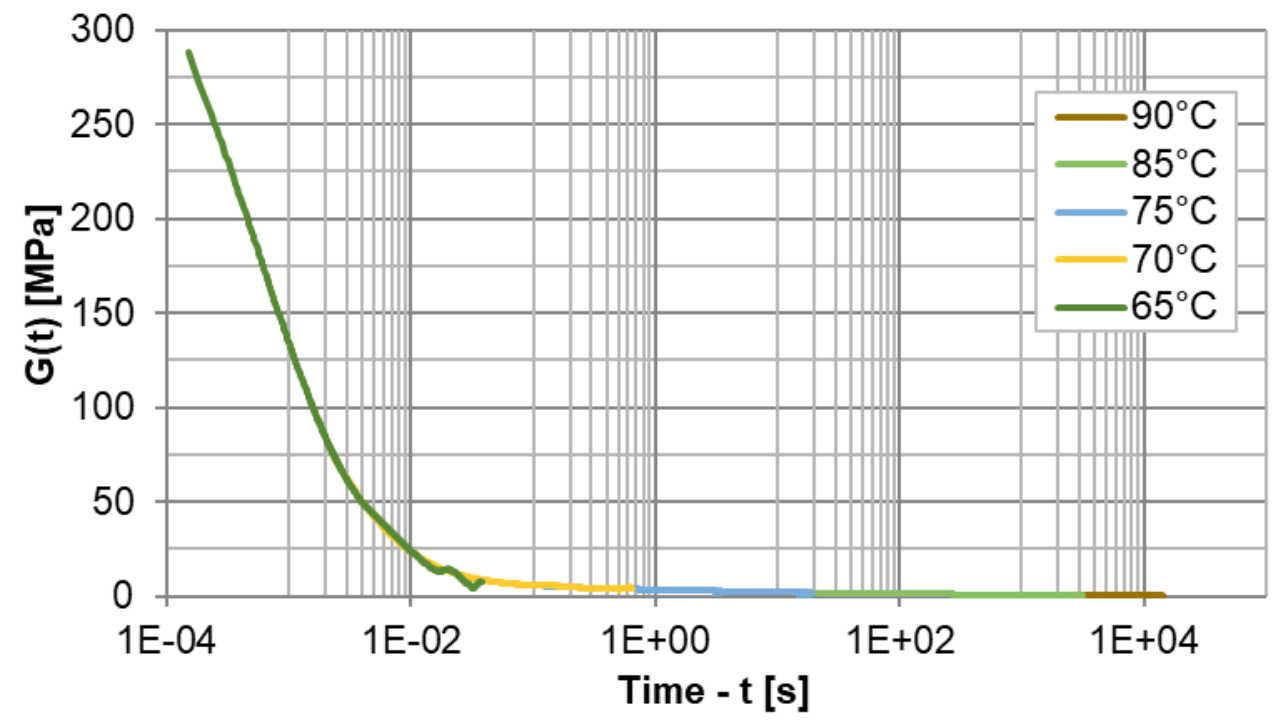

Fig.11 Partial master curve at a reference temperature of $85^{\circ} \mathrm{C}$ 

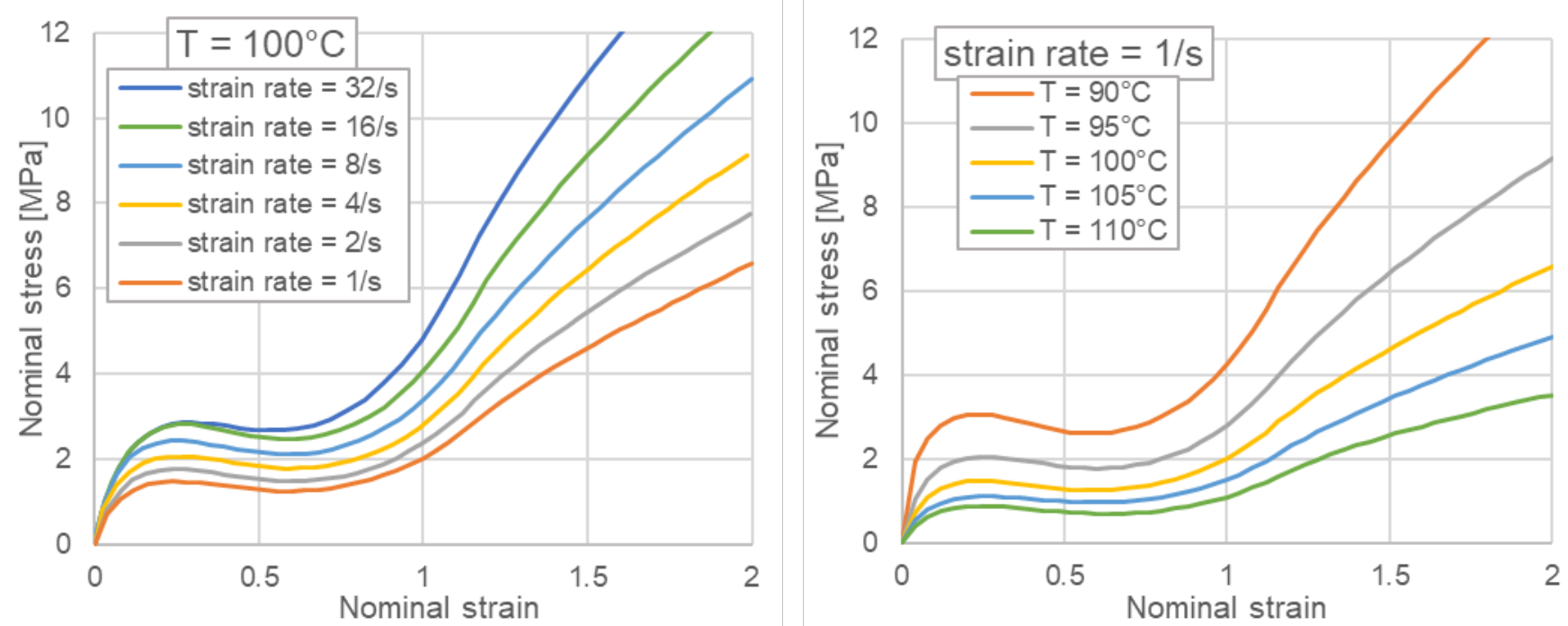

Fig.12 Nominal stress-strain curves resulted from finite element biaxial test simulations at different strain rates and temperatures 


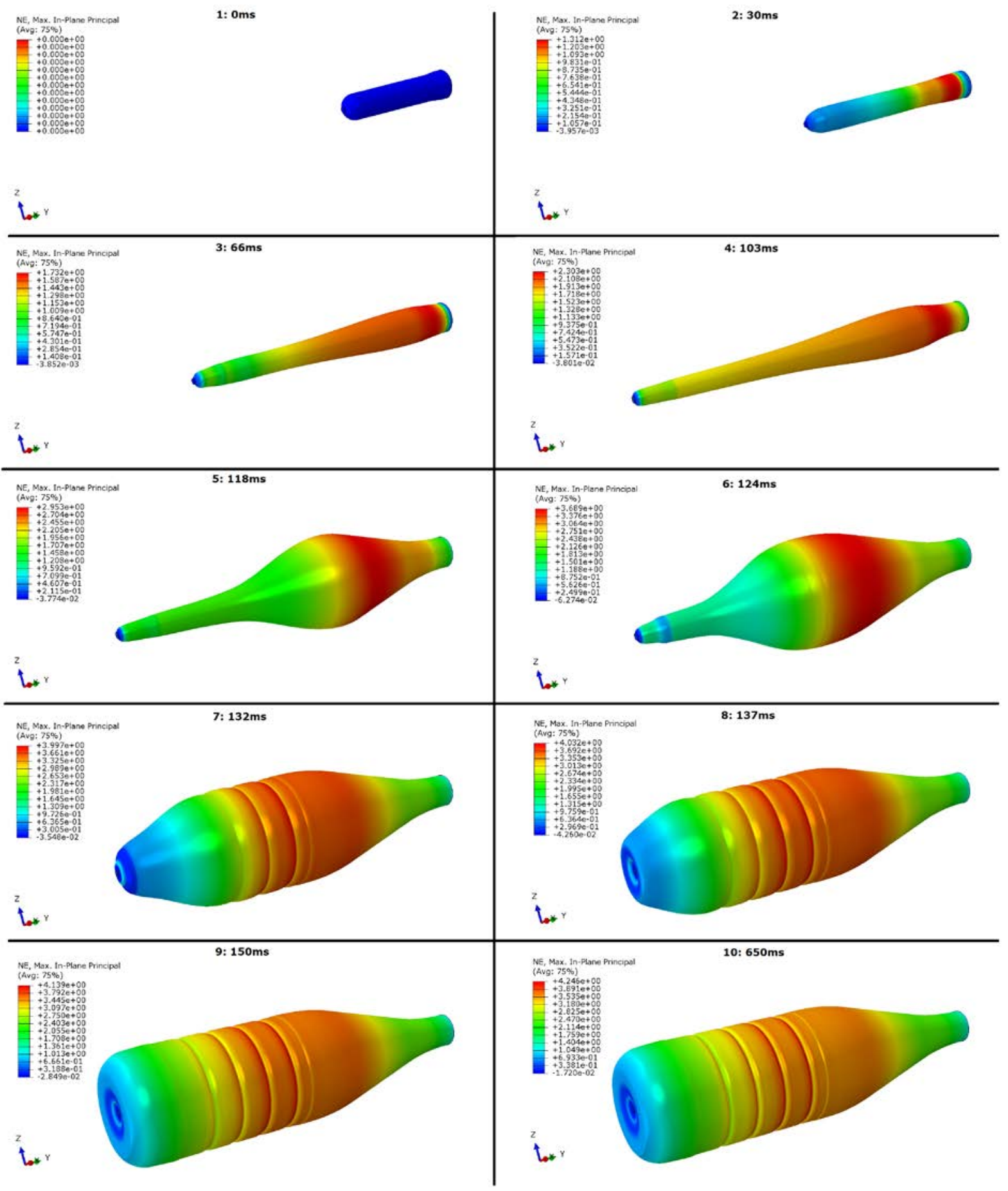

Fig.13 Time history of the maximum principal nominal strain over the whole bottle 


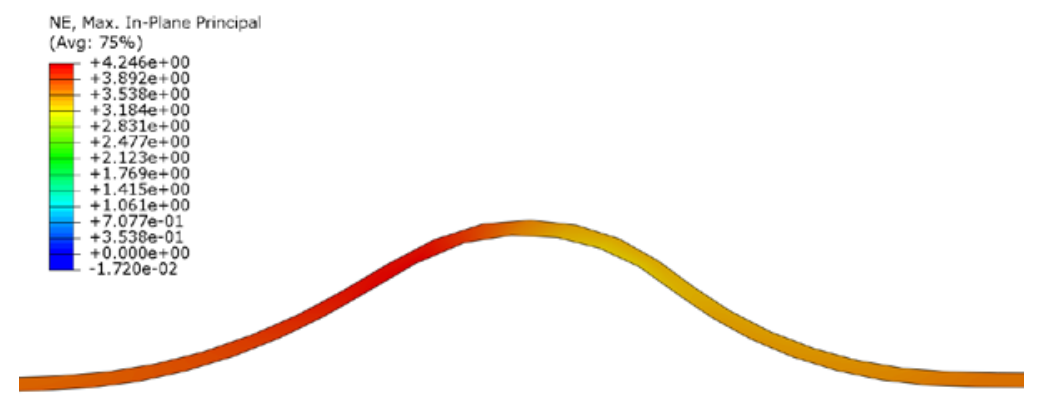

Fig.14 Maximum principal nominal strain at the most critical spot of the bottle (point A) at the end of the ISBM process
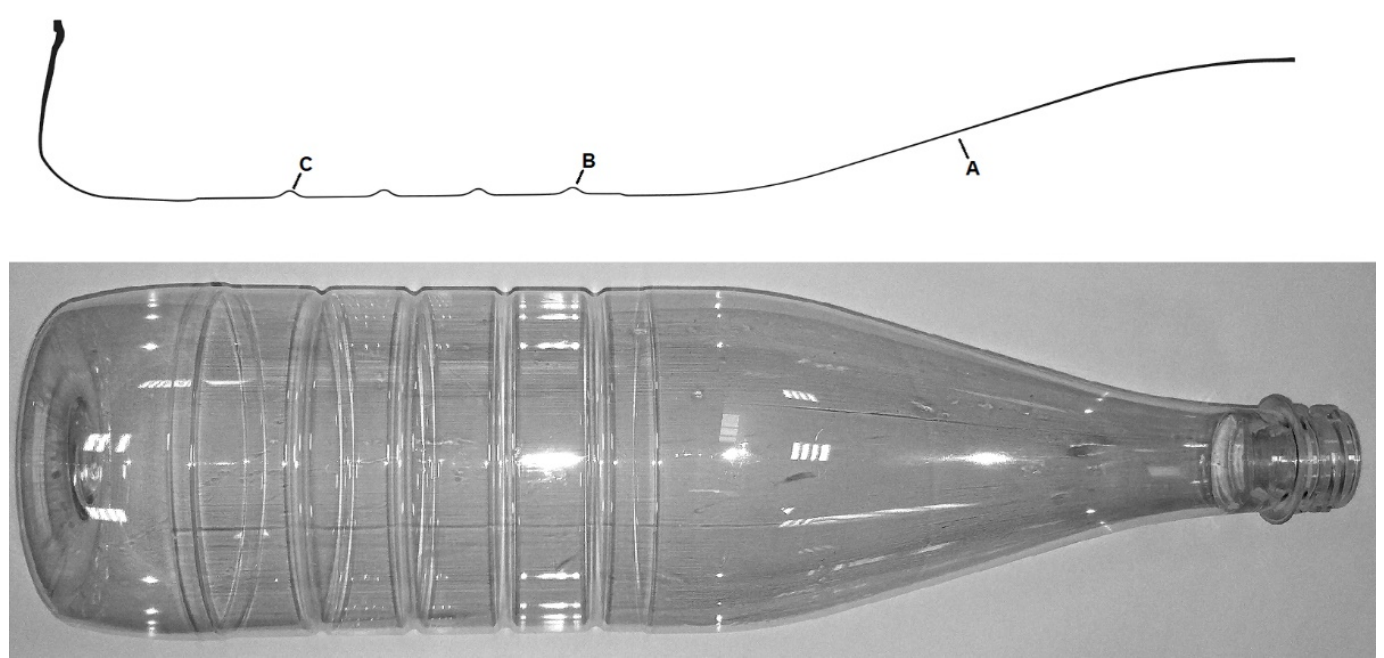

Fig.15 Thickness of the profile at the end of the ISBM process and measurement and Real bottle obtained via ISBM

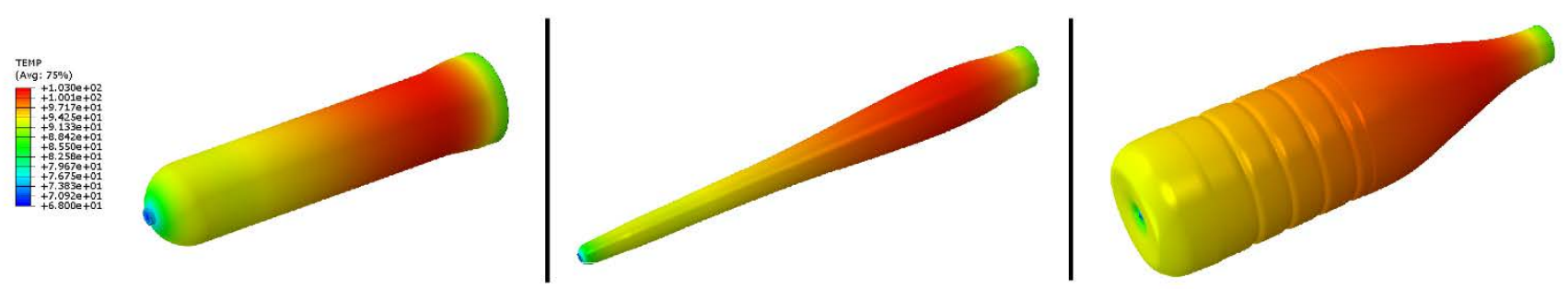

Fig.16 Temperature $\left[{ }^{\circ} \mathrm{C}\right]$ field applied to the preform at different deformation levels 


\begin{tabular}{|c|c|}
\hline $\boldsymbol{\tau}_{\boldsymbol{i}}$ [s] & $\boldsymbol{g}_{\boldsymbol{i}}$ \\
\hline 0.0121 & $1.15 \mathrm{E}-07$ \\
\hline 0.0500 & $3.48 \mathrm{E}-07$ \\
\hline 0.186 & $2.53 \mathrm{E}-06$ \\
\hline 0.180 & $1.46 \mathrm{E}-05$ \\
\hline 0.194 & $8.87 \mathrm{E}-05$ \\
\hline 0.234 & 0.000687 \\
\hline 0.102 & 0.00316 \\
\hline 0.0309 & 0.0139 \\
\hline 0.00479 & 0.106 \\
\hline 0.00193 & 1.30 \\
\hline 0.00169 & 15.1 \\
\hline 0.00112 & 387 \\
\hline 0.000638 & 595 \\
\hline
\end{tabular}

Table 1 Coefficients of the Prony series

\begin{tabular}{|c|c|c|c|}
\hline $\begin{array}{c}\text { Measurement } \\
\text { location }\end{array}$ & $\begin{array}{c}\text { Thickness [mm] } \\
\text { FEM simulation }\end{array}$ & $\begin{array}{c}\text { Thickness [mm] } \\
\text { FEM simulation* }\end{array}$ & $\begin{array}{c}\text { Thickness [mm] } \\
\text { Experimental test }\end{array}$ \\
\hline A & 0.26 & 0.26 & 0.26 \\
\hline B & 0.135 & 0.17 & 0.18 \\
\hline C & 0.162 & 0.19 & 0.19 \\
\hline
\end{tabular}

Table2 Comparison of thickness measurements on three different points of the bottle (numerical vs experimental). The second column (FEM simulation*) shows the thickness measured at the time each point comes into contact with the mould. 